\title{
Inhibitory effects of brusatol delivered using glycosaminoglycan-placental chondroitin sulfate A-modified nanoparticles on the proliferation, migration and invasion of cancer cells
}

\author{
XIN CHEN $^{1^{*}}$, TAILANG YIN ${ }^{1 *}$, BAOZHEN ZHANG $^{2,3^{*}}$, BEINI SUN $^{4}$, JIE CHEN $^{2}$, TIANXIA XIAO ${ }^{2}$, \\ BAOBEI WANG ${ }^{2}$, MENGXIA LI ${ }^{2}$, JING YANG $^{1}$ and XIUJUN FAN ${ }^{2}$ \\ ${ }^{1}$ Reproductive Medical Center, Renmin Hospital of Wuhan University and Hubei Clinic Research Center for Assisted \\ Reproductive Technology and Embryonic Development, Wuhan, Hubei 430060; ${ }^{2}$ Laboratory for Reproductive Health, \\ Shenzhen Institutes of Advanced Technology, Chinese Academy of Sciences, Shenzhen, Guangdong 518052; \\ ${ }^{3}$ University of Chinese Academy of Sciences, Beijing 100049; ${ }^{4}$ Key Laboratory of Microbiology, \\ College of Heilongjiang Province, School of Life Science, Heilongjiang University, \\ Harbin, Heilongjiang 150080, P.R. China
}

Received December 6, 2019; Accepted May 13, 2020

DOI: $10.3892 /$ ijmm.2020.4627

\begin{abstract}
Breakthroughs in cancer management result from the development of drugs that can be used for early diagnosis and effective treatment. Surgery, chemotherapy, radiotherapy and hormone therapy are the main anticancer therapies. However, traditional cancer chemotherapy is associated with serious systemic side effects. Nanoparticles (NPs) provide an effective solution for cancer treatment via the targeted delivery of drugs to cancer cells, while minimizing injury to normal cells. Glycosaminoglycan-placental chondroitin sulfate A (plCSA) is expressed in a number of tumor cells and trophoblasts. A plCSA-binding peptide (plCSA-BP) was isolated from malaria protein VAR2CSA, which can effectively promote the binding of lipid polymer NPs to tumor cells, thereby significantly enhancing the anticancer effect of encapsulated drugs. Brusatol
\end{abstract}

Correspondence to: Professor Jing Yang, Reproductive Medical Center, Renmin Hospital of Wuhan University and Hubei Clinic Research Center for Assisted Reproductive Technology and Embryonic Development, 238 Jiefang Road, Wuhan, Hubei 430060, P.R. China

E-mail: 13507182023@163.com

Professor Xiujun Fan, Laboratory for Reproductive Health, Shenzhen Institutes of Advanced Technology, Chinese Academy of Sciences, 1068 Xueyuan Avenue, Shenzhen, Guangdong 518052, P.R. China

E-mail: xiujun.fan@gmail.com

*Contributed equally

Key words: brusatol, placental chondroitin sulfate A, nanoparticles, drug delivery, tumor targeting, proliferation, migration, invasion is an important compound derived from Brucea javanica that exerts a multitude of biological effects, including inhibiting tumor cell growth, reducing the reproduction of malaria parasites, reducing inflammation and resisting virus invasion. In the present study, brusatol-loaded NPs (BNPs) or coumarin 6 NPs (CNPs), plCSA-BP and scrambled control peptide-bound BNPs or CNPs were prepared. Ovarian cancer cells (SKOV3), endometrial cancer cells (HEC-1-A) and lung cancer cells (A549) were treated with the NPs. The uptake of plCSA-CNPs by tumor cells was found to be markedly higher compared with that of other types of NPs. Further studies demonstrated that the plCSA-BNPs promoted the apoptosis of cancer cells more effectively and inhibited their proliferation, invasion and migration, accompanied by downregulation of matrix metalloproteinase (MMP)-2, MMP-9 and B-cell CLL/lymphoma 2 (BCL2) levels, but upregulation of BCL2-associated X protein BAX and cleaved caspase-3 levels. The results demonstrated the potential of brusatol delivered by plCSA-modified NPs as a chemotherapeutic agent for the targeted therapy of tumors by regulating the BCL2, BAX, cleaved caspase-3, MMP-2 and MMP-9 pathways, and indicated that it may be an effective and safe strategy for the treatment of various tumors.

\section{Introduction}

In recent years, screening cancer therapeutic drugs from natural products has become a focus in cancer prevention and treatment research. The efficacy of traditional Chinese medicines and their extracts in the treatment of diseases has been recognized, and more effective drugs for treating tumors are being identified. Brucea javanica is a shrub that mainly grows in Asia, particularly in southern China, and is used to treat a variety of diseases, such as malaria (1), amoebic dysentery (2) and tumors (3). Brusatol (BRU), an important component extracted from Brucea javanica (2), exerts a multitude of 
biological effects, including inhibiting the growth of tumor cells, reducing the reproduction of malaria parasites, reducing inflammation and resisting virus invasion (4). Clinical trials have demonstrated that BRU is a potential anticancer drug with potent cytotoxicity towards several types of cancer cells, including colorectal cancer (5), pancreatic cancer (6) and lung cancer (7). In addition, BRU can enhance the sensitivity of cancer cells to chemotherapeutic drugs by specifically blocking the expression of nuclear factor erythrocyte 2 related factor 2 (NRF2) $(7,8)$. These findings suggest that BRU may be an effective antineoplastic drug and may be developed as a chemotherapeutic adjuvant for the treatment of a variety of tumors (9). Unfortunately, BRU is associated with several toxicities, including cardiac ischemia/reperfusion injury (10). It also reverses the therapeutic effects of other drugs, leading to aggravation of neuroinflammation and nerve injury (11), septicemic kidney injury (12), liver injury (13) and intestinal epithelial cell injury (14). These toxicities are attributed to the inhibition of NRF2. Furthermore, other studies have reported that BRU can affect the early development of mouse embryos and exerts toxic effects on mouse oocytes $(15,16)$. However, the response rate to most chemotherapeutics in the treatment of human cancer remains low, and there is an urgent need for developing new and safe therapeutic agents.

Cancer is one of the most devastating diseases and constitutes a major threat to global public health and quality of life. Cancer is the second most fatal disease after cardiovascular disease in developed and developing countries (17). There were a reported 9.6 million deaths and 18.1 million new cancer cases worldwide in $2018(18,19)$. Lung cancer is one of the most common malignant tumors and a leading cause of cancer-related mortality (20), whereas endometrial and ovarian cancers are the most common malignant tumors of the female reproductive system. The incidence of ovarian cancer is slightly lower compared with that of endometrial cancer (21). In the early stages of the three cancers mentioned above, the symptoms are not obvious; therefore, these cancers are often diagnosed after extensive metastasis has occurred, and the treatment methods are ineffective, resulting in poor prognosis (22-24). Therefore, with the rapid increase of cancer cases worldwide, it is crucial to develop and screen potential anticancer drugs (25). However, the currently available anticancer drugs can cause serious side effects and complications. Therefore, there is an urgent need for effective and low-toxicity treatment methods, and for innovative anticancer strategies in order to reduce the mortality of patients with malignant tumors and improve their quality of life (26).

Targeted drug therapy using nanoparticles (NPs) is a new method of cancer treatment, which greatly improves the therapeutic effect of several existing drugs $(27,28)$. The effectiveness of NPs and selective killing of cancer cells have been confirmed in several studies (29-31). A major study reported that glycosaminoglycan-placental chondroitin sulfate A (plCSA) is widely expressed in human tumors, with absent-to-low expression in normal tissues other than the placenta (32). In addition, our previous research demonstrated that plCSA-binding peptide (plCSA-BP) lipid polymer NPs could rapidly bind to choriocarcinoma cells and notably enhance the anticancer activity of doxorubicin in vivo (33). Therefore, the use of plCSA-targeting lipid polymer NPs to treat human cancers is a newly recognized tool for delivering drugs to cancer cells, while minimizing the risk of injury to normal cells.

In the present study, plCSA-targeted lipid polymer NPs that encapsulated BRU were used to validate its efficiency and targeting of various tumors in vitro, such as lung, endometrial and ovarian cancer. The uptake of plCSA-coumarin 6 NPs (CNPs) by tumor cells was compared to that of other types of NPs, and it was investigated whether plCSA-brusatol-loaded NPs (BNPs) effectively promoted the apoptosis of cancer cells and inhibited their proliferation, invasion and migration through regulating the B-cell CLL/lymphoma 2 (BCL2), BCL2-associated X protein (BAX), cleaved caspase-3, matrix metalloproteinase (MMP)-2 and MMP-9 pathways.

\section{Materials and methods}

Experimental materials. Soybean lecithin and 1,2-distearoylsn-glycero-3-phosphoethanolamine-N-[carboxy (polyethylene glycol)-2000] (DSPEPEG-COOH) were purchased from Avanti Polar Lipids, Inc. Poly(DL-lactic-co-glycolic acid) (50:50) (PLGA), 1-ethyl-3-(3-dimethylaminopropyl) carbodiimide hydrochloride (EDC), and N-hydroxysuccinimide (NHS), were purchased from Sigma-Aldrich; Merck KGaA. The plCSA-binding peptide (EDVKDINFDTKEKFLAGC LIVSFHEGKC) and the scrambled peptide (SCR; EVDNDK KLGLVFEKDKIFTEFACISHCG) were synthesized by ChinaPeptides Co., Ltd. and Shanghai GL Biochem Co. Ltd. BRU was purchased from Absin. Transwell 24-well 8.0- $\mu \mathrm{m}$ pore transparent plates were purchased from BD Biosciences. Matrigel was purchased from Corning, Inc. The Cell Counting Kit-8 (CCK-8) was purchased from Dojindo Molecular Technologies, Inc. The anti-Bcl-2-associated X protein (BAX) (cat. no. 2774), anti-B-cell lymphoma (BCL)-2 (cat. no. 2875), anti -cleaved caspase-3 (cat. no. 9661), anti-MMP-2 (cat. no. 40994), anti-MMP-9 (cat. no. 13667) and anti-GAPDH (cat. no. 5174) were purchased from Cell Signaling Technology, Inc. All other materials were obtained from Sigma-Aldrich; Merck $\mathrm{KGaA}$, unless otherwise specified.

BNPs or CNPs were synthesized using a single-step sonication method using PLGA, soybean lecithin, BRU or coumarin 6, and DSPE-PEG-COOH. PLGA was dissolved in acetonitrile, and soybean lecithin and DSPE-PEG-COOH were dissolved in $4 \%$ ethanol solution. BRU was dissolved in DMSO at a concentration of $10 \mathrm{mg} / \mathrm{ml}$ and coumarin 6 was dissolved in DMSO at a concentration of $1 \mathrm{mg} / \mathrm{ml}$. To prepare BNPs, $750 \mu \mathrm{g}$ of BRU, $90 \mu \mathrm{g}$ of soybean lecithin and $210 \mu \mathrm{g}$ of DSPE-PEGCOOH were added into $3 \mathrm{ml}$ of $4 \%$ ethanol aqueous solution, and then an ultrasonic processor (VCX 130; Sonics \& Materials) was used to treat the solution. The frequency of the ultrasonic processor was $20 \mathrm{kHz}$, the power was $30 \mathrm{~W}$, and the time interval was $5 \mathrm{~min}$. The BNPs were then centrifuged $(34,000 \mathrm{x} \mathrm{g})$ for $30 \mathrm{~min}$ at $4^{\circ} \mathrm{C}\left(\mathrm{Optima}^{\mathrm{TM}}\right.$ MAX-XP; Beckman Coulter, Inc.). After centrifugation, the supernatant was removed, and the precipitate was resuspended in $1 \mathrm{ml}$ of PBS ( $\mathrm{pH}$ 7.4). The NPs were purified by washing in PBS through an Amicon Ultra-4 centrifugal filter (molecular weight cut-off, $10 \mathrm{kDa}$; EMD Millipore), and these steps were repeated three times. CNPs were prepared using the same method. 
Conjugation of plCSA-BP or SCR to the NPs. EDC/NHS technology was used to bind peptides to the surface of the NPs. In brief, to bind plCSA-BP or SCR to the BNP surface, activation buffer, EDC and NHS were added, and the molar ratio of DSPE-PEG-COOH:NHS:EDC was 1:2:2 to activate the carboxyl groups. The EDC/NHS solution and BNPs were mixed at room temperature for $30 \mathrm{~min}$, and then plCSA-BP or SCR were added. The mixture was stirred at room temperature for $1-2 \mathrm{~h}$, and then stored overnight at $4^{\circ} \mathrm{C}$. To remove the unbound peptide, the product was reconstituted and purified as described above. PICSA-BP and SCR-conjugated CNPs were prepared using the same method.

Encapsulation efficiency (EE) and drug loading efficiency (LE) of BRU in the NPs. The EE and LE of BRU in the NPs were determined as described below. First, the following steps were used to produce a standard curve: BRU was dissolved in DMSO at concentrations of $1,5,10,20,30,50$ and $80 \mu \mathrm{g} / \mathrm{ml}$. The absorption of the BRU solution at $280 \mathrm{~nm}$ was measured using an ultraviolet visible (UV-vis) spectrophotometer (f900, Edinburgh Instruments Ltd.), and then the standard curve was generated according to the concentration of BRU. Subsequently, $25 \mu 1$ of NPs were diluted with $500 \mu 1$ of ultra-pure water, and the absorption at $280 \mathrm{~nm}$ was measured using the UV-vis spectrophotometer. The drug concentration was calculated using the standard curve. The EE and LE were calculated as follows: $\mathrm{EE}=$ (amount of drug in NPs/amount of added drug) $\mathrm{x} 100 \%$; and $\mathrm{LE}=$ (amount of drug in NPs/total weight of materials) $\mathrm{x} 100 \%$.

Cell culture and treatment. The human ovarian adenocarcinoma cell line SKOV3 was obtained from Wuhan Boster Biological Technology, Ltd. The human lung epithelial cell adenocarcinoma cell line A549 was obtained from the Shanghai Institute of Cell Biology, Chinese Academy of Sciences. The human endometrial adenocarcinoma cell line HEC-1-A, the normal human ovarian epithelial cell line IOSE80, human endometrial stromal cells (hESCs), and the normal human lung epithelial cells BEAS-2B, were purchased from BeNa Culture Collection. The A549 cells were grown in DMEM; the SKOV3 and HEC-1-A cell were maintained in McCoy's 5A medium; IOSE80 and BEAS-2B cells were cultured in RPMI-1640 medium; and hESCs were cultured in DMEM/F12 supplemented with 10\% FBS (Gibco; Thermo Fisher Scientific, Inc.), $100 \mu \mathrm{g} / \mathrm{ml}$ streptomycin and $100 \mathrm{U} / \mathrm{ml}$ penicillin G. Apart from the different media, all the cell culture conditions were the same as mentioned above. All cells were placed in a cell culture chamber with $5 \% \mathrm{CO}_{2}$ at $37^{\circ} \mathrm{C}$ with sufficient saturated humidity.

BRU does not emit light; therefore, coumarin 6 was used instead of BRU to treat cells, in order to observe the rate of uptake of the NPs. First, cells were grown to $70-80 \%$ confluence and treated with free coumarin 6, CNPs, SCR-CNPs, or the plCSA-CNPs, in 24-well plates for $1 \mathrm{~h}$ at $4^{\circ} \mathrm{C}$. The cells were washed with PBS to remove unconjugated coumarin 6 or NPs, and incubated for $30 \mathrm{~min}$ at $37^{\circ} \mathrm{C}$. Only surface-bound NPs were allowed to internalize. The cells in each group were then fixed at room temperature for $15 \mathrm{~min}$ with $4 \%$ paraformaldehyde, stained with 2-(4-amidinophenyl)-1H-indole-6-carboxamidine (DAPI) for $10 \mathrm{~min}$ at room temperature, washed with PBS three times, and fixed at room temperature for 15 min with 4\% paraformaldehyde. Finally, the cells of each group were observed under an inverted fluorescence microscope (IX73; Olympus Corporation) at a magnification of x200. Four visual fields were randomly selected to calculate the fluorescence intensity.

Detection of in vitro cell viability using the CCK-8 assay. The CCK-8 method was used to detect the effect of different treatments on the viability of tumor cells (SKOV3, HEC-1-A and A549) and normal cells (IOSE80, hESCs and BEAS-2B). Cells in the logarithmic growth phase were digested with trypsin. Thereafter, the cell concentration was adjusted to 10,000 cells $/ \mathrm{ml}$ and the cells were inoculated into a 96-well plate at a density of $100 \mu \mathrm{l} /$ well. Subsequently, the free BRU, BNPs, SCR BNPs, or plCSA-BNPs at concentrations of $0,0.2$, $0.4,0.6,0.8,1$ and $2 \mu \mathrm{g} / \mathrm{ml}$ were added to the culture cells for drug intervention. Each concentration was set with six replicate wells. The plates were cultured at $37^{\circ} \mathrm{C}$ and $5 \% \mathrm{CO}_{2}$. After $48 \mathrm{~h}$ of cell culture, $20 \mu \mathrm{l}$ of CCK- 8 solution was added to each well. The cells were incubated for $1 \mathrm{~h}$ before the reaction was terminated and detected using an automatic enzyme marker.

Apoptosis assay using PE Annexin $V$ staining. The cellular apoptosis rate was determined using a PE Annexin V Apoptosis Detection kit I (BD Biosciences) according to the manufacturer's protocol. Briefly, tumor cells (SKOV3, HEC-1-A and A549) and normal cells (IOSE80, hESCs and BEAS-2B) were seeded into 6-well plates and treated with free BRU or plCSA-BNPs for $24 \mathrm{~h}$. On the following day, the cells were harvested, washed twice with cold PBS, resuspended in $500 \mu 1$ of binding buffer, and stained with $5 \mu 17-\mathrm{AAD}$ and $5 \mu \mathrm{PE}$ Annexin $\mathrm{V}$ for $15 \mathrm{~min}$ at room temperature $\left(25^{\circ} \mathrm{C}\right)$ in the dark. Fluorescence signals from at least 10,000 cells were analyzed immediately using a FACSCalibur flow cytometer (BD Biosciences). Dot plots and histograms were analyzed using FlowJo software, v7.6.1 (FlowJo, LLC).

Wound healing and Transwell invasion assays. For the cell invasion assay, pure Matrigel was diluted with PBS at a ratio of 1:20, and then the diluted Matrigel was added to the upper surface of the Transwell filter and placed in the incubator at $37^{\circ} \mathrm{C}$ for $2 \mathrm{~h}$. Subsequently, cells treated with free BRU or plCSA-BNPs for $24 \mathrm{~h}$ were inoculated into the upper chamber in $200 \mu 1$ of culture medium without FBS, and $600 \mu \mathrm{l}$ of culture medium with $10 \%$ FBS was added into the plate. After 2 days of incubation, the cells attached to the upper surface of the filter were removed with cotton swabs, and the cells remaining on the lower surface were fixed with $4 \%$ paraformaldehyde for $15 \mathrm{~min}$ at room temperature and stained with $0.5 \%$ crystal violet solution for $10 \mathrm{~min}$ at room temperature. Subsequently, cells invading the lower surface were counted in five random fields (magnification, x100) under an inverted fluorescence microscope (IX73; Olympus Corporation). For the migration assay, cells were seeded into 6-well plates until $\sim 100 \%$ confluent, and the confluent cell layer on an agar plate was scratched with a $200-\mu 1$ pipette tip. The cells were then washed with PBS and treated with free BRU or plCSA-BNPs, then incubated in serum-free medium. The degree of wound closure in each case was imaged and plotted at 0 and $24 \mathrm{~h}$. 
A

A SKOV3 B

B

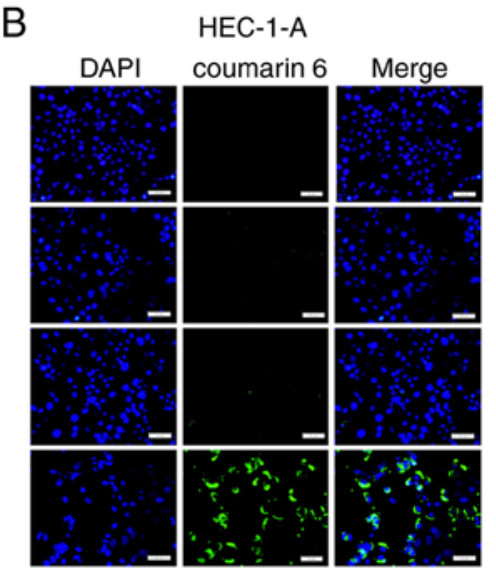

C

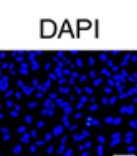

A549
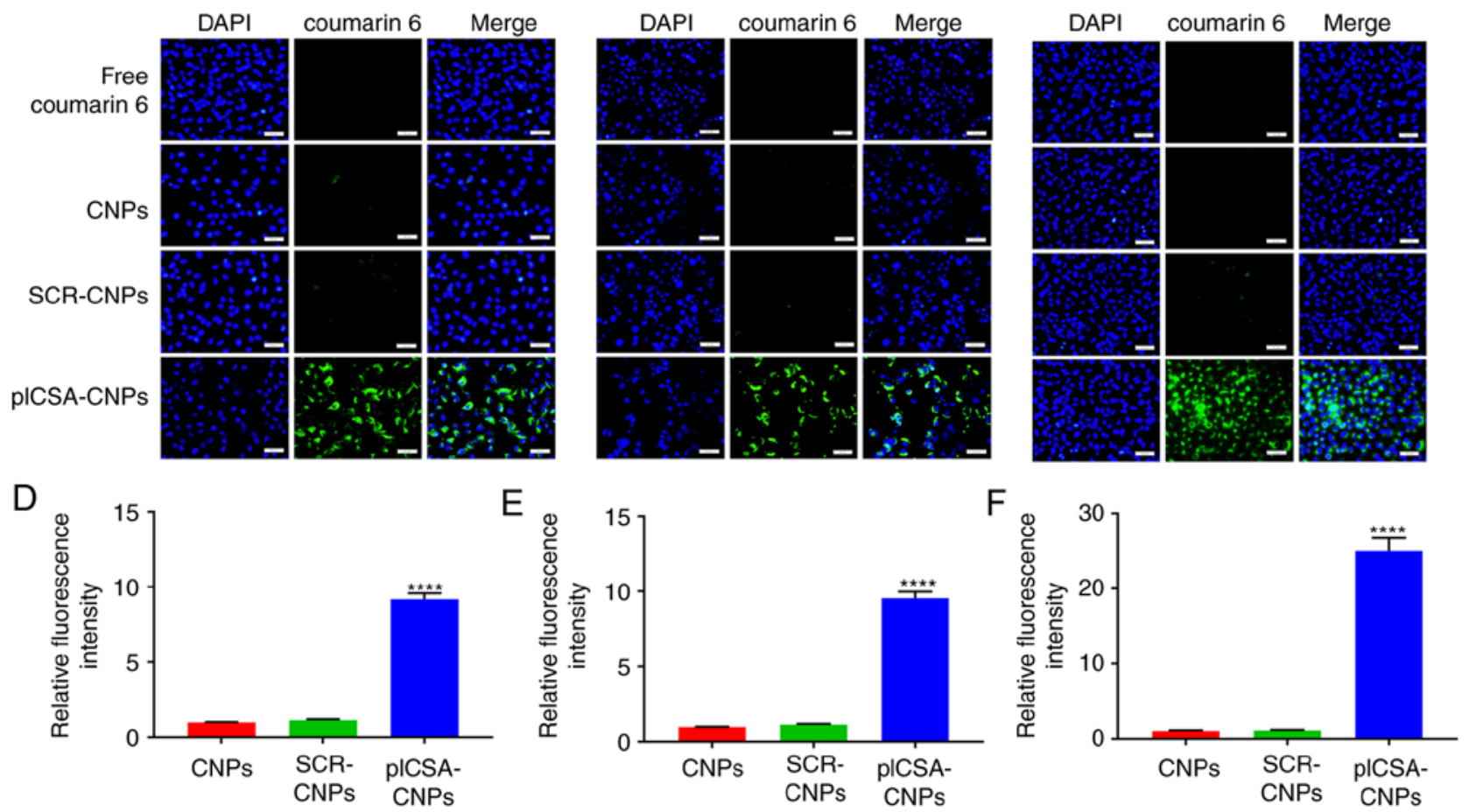

Figure 1. In vitro cell uptake of nanoparticles. (A) The human ovarian adenocarcinoma cell line SKOV3, (B) the human endometrial adenocarcinoma cell line HEC-1-A and (C) the human epithelial lung adenocarcinoma cell line A549 were analyzed by fluorescence microscopy after a 30-min incubation with $5 \mu \mathrm{g} / \mathrm{ml}$ of different coumarin 6-loaded nanoparticles. Four visual fields were randomly selected to calculate the fluorescence intensity of nanoparticle uptake by (D) SKOV3, (E) HEC-1-A and (F) A549 cells. One-way ANOVA was used to analyze the significance of the differences among groups, followed by Tukey's post hoc test. Values are expressed as means \pm standard deviation. ${ }^{* * * * *} \mathrm{P}<0.0001$. The experiments were repeated three times. Scale bar, $50 \mu \mathrm{m}$. CNPs, coumarin 6-loaded nanoparticles; SCR, scramble; plCSA, placental chondroitin sulfate A.

Western blotting. Free BRU or plCSA-BNPs were added to cells in the logarithmic growth phase and incubated at $37^{\circ} \mathrm{C}$ for $24 \mathrm{~h}$. The cells were lysed by grinding on ice in RIPA buffer at $4^{\circ} \mathrm{C}$ for $30 \mathrm{~min}$. The lysate was centrifuged at $12,000 \times \mathrm{g}$ at $4^{\circ} \mathrm{C}$ for $10 \mathrm{~min}$. One part of the supernatant was used to detect the protein concentration using a BCA Protein Assay kit (Beyotime Institute of Biotechnology). The other part of the supernatant was added $4 \mathrm{X}$ sample buffer, boiled for denaturation, and then subjected to SDS-PAGE with a $4 \%$ concentrating gel and a $10 \%$ separation gel. Subsequently, the separated proteins were transferred onto PVDF membranes (EMD Millipore). The membranes were then blocked with 5\% non-fat dry milk in Tris-buffered saline with $0.1 \%$ Tween 20 (TBST) for $1.5 \mathrm{~h}$ and incubated with the primary antibodies (BAX, 1:1,000 dilution; BCL2 , 1:1,000 dilution; cleaved caspase-3, 1:1,000 dilution; MMP-2, 1:1,000 dilution; MMP-9, 1:1,000 dilution; and GAPDH, 1:1,000 dilution) at $4^{\circ} \mathrm{C}$ overnight. After washing with TBST three times, the membranes were further incubated with the secondary antibody (cat. no. SA00001-2; 1:5,000 dilution; goat anti-rabbit; ProteinTech Group, Inc.) for $1 \mathrm{~h}$ at room temperature, and the color was developed using ECL chemiluminescent solution (Beyotime Institute of Biotechnology). Finally, images were acquired and the optical density value of the immunoreactive protein bands were analyzed using Image $\mathbf{J}$ software, version 1.51j8 (Media Cybernetics, Inc.). Loading was normalized using GAPDH.

Statistical analysis. All experimental data are expressed as the mean \pm standard deviation of at least three independent experiments. GraphPad Prism 7.0 (GraphPad Software, Inc.) was used for the statistical analysis. One-way ANOVA followed by Tukey's post hoc test and two-way ANOVA followed by Bonferroni's post hoc test was used to analyze the differences among groups. $\mathrm{P}<0.05$ was considered to indicate statistically significant differences.

\section{Results}

Characterization of NPs. The drug EE and LE of the NPs are crucial to ensure a successful drug delivery system. The EE and LE of BRU in the NPs were calculated by constructing standard curves. The EEs of BRU for the BNPs, SCR-BNPs and plCSA-BNPs were $40.3 \pm 1.67,38.8 \pm 1.83$ and $39.5 \pm 1.94 \%$, respectively. The LEs of BRU for the BNPs, SCR-BNPs and plCSA-BNPs were $6.2 \pm 0.74,5.3 \pm 0.56$ and $5.1 \pm 0.42 \%$, respectively. These data indicate that the extent of drug loading and drug encapsulation was maintained after plCSA-BP decoration of the NPs.

In vitro cellular uptake assay of the NPs. In order to test whether the combination of plCSA-BP with nanocarriers could increase the absorption of NPs by the tumors, the SKOV3, HEC-1-A and A549 cell lines were cultured with different NPs. Fluorescence microscopy demonstrated that cancer cells treated with plCSA-CNPs had a higher fluorescence intensity compared with that of the other treatments. Moreover, in SKOV3, HEC-1-A and A549 cells, the NP uptake of the targeted preparation into the cells was $>9$ times that of 
A

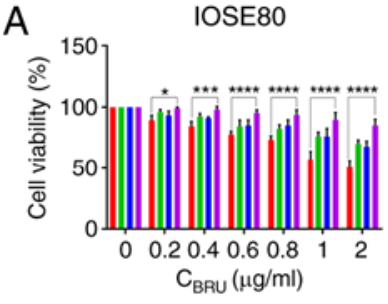

B
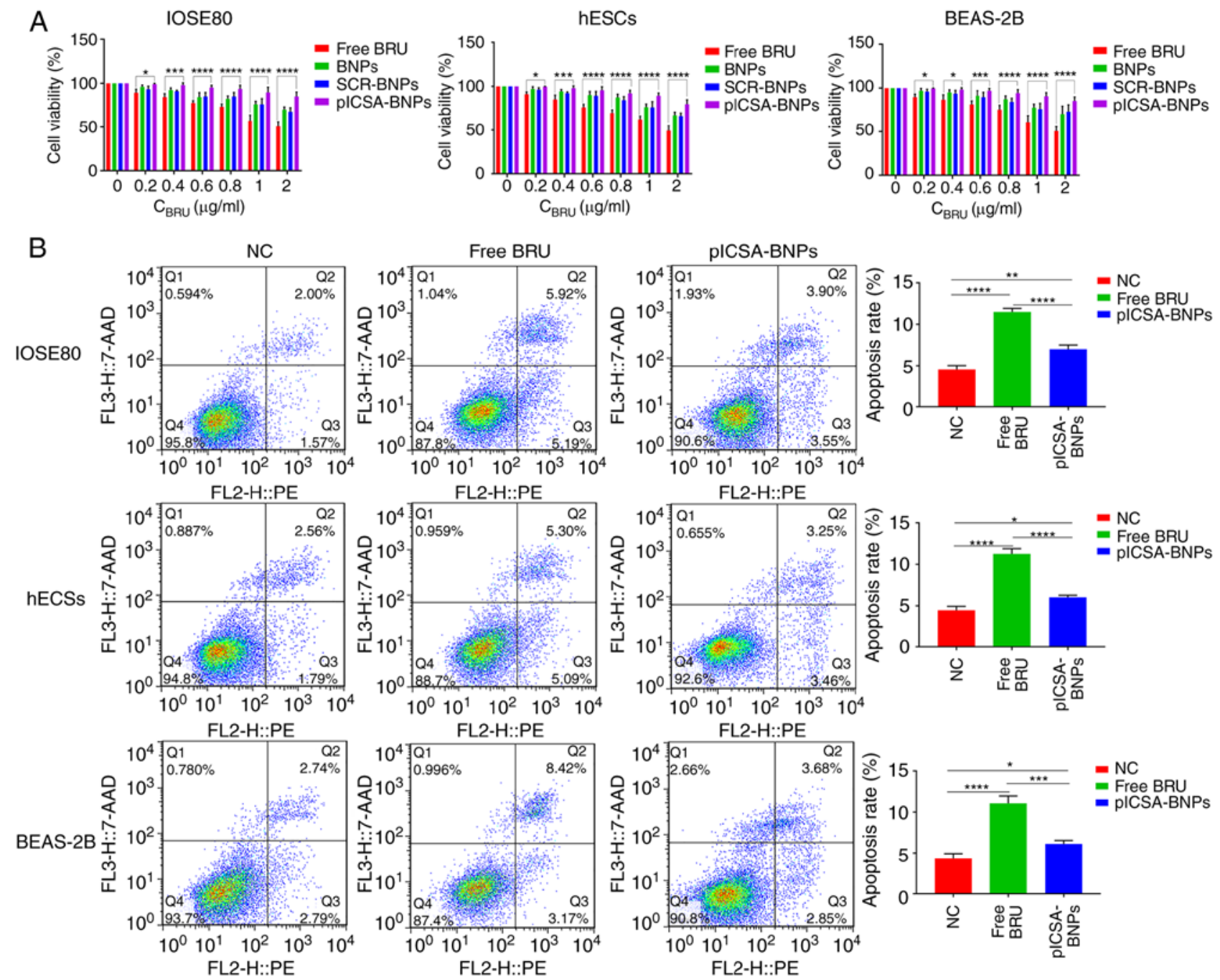

Figure 2. plCSA-BNPs reduce the cytotoxicity of BRU. (A) Quantitative evaluation of the viability of different normal cells treated with free BRU and the different nanoparticles for $24 \mathrm{~h}$ using the Cell Counting Kit- 8 assay. Two-way ANOVA was used to analyze the significance of the differences among groups, followed by Bonferroni's post hoc test. (B) After stimulation with free BRU and the different nanoparticles for $24 \mathrm{~h}$, the apoptosis rate of different normal cells was detected using flow cytometry. One-way ANOVA was used to analyze the significance of the differences among groups, followed by Tukey's post hoc test. Values are expressed as means \pm standard deviation. ${ }^{*} \mathrm{P}<0.05,{ }^{* *} \mathrm{P}<0.01,{ }^{* * *} \mathrm{P}<0.001,{ }^{* * * *} \mathrm{P}<0.0001$. The experiments were repeated three times. IOSE80, human normal ovarian epithelial cell line; hESCs, human endometrial stromal cells; BEAS-2B, human normal lung epithelial cells; BRU, brusatol; plCSA, placental chondroitin sulfate A; BNPs, BRU-loaded nanoparticles; NC, negative control.

the non-targeted control $(\mathrm{P}<0.0001 ;$ Fig. 1A-F). These results suggest that the plCSA-targeting agent-absorbed NPs had a better targeting efficiency compared with the non-targeted controls. In addition, the combination with SCR did not lead to enhanced uptake of NPs by the different cancer cells, indicating the specific role of plCSA in the uptake by tumor cells.

Toxicity of BRU and plCSA-BNPs toward normal cells. In order to evaluate the effect of BRU and plCSA-BNPs on normal cells, the CCK-8 method was used to determine the cytotoxicity of different NPs after $24 \mathrm{~h}$. The results revealed that $0-2 \mu \mathrm{g} / \mathrm{ml}$ of BRU could significantly inhibit the growth of normal cells (IOSE80, hESCs and BEAS-2B), and the cytotoxicity increased with increasing BRU concentration. However, the toxicity of plCSA-BNPs toward normal cell lines was significantly lower compared with that of free BRU (Fig. 2A). The P-values of IOSE80 cells treated with plCSA-BNPs at 0.2 , $0.4,0.6,0.8,1$ and $2 \mu \mathrm{g} / \mathrm{ml}$ compared with that of cells treated with free BRU were $0.0163,0.0003,<0.0001,<0.0001,<0.0001$ and $<0.0001$, respectively. The P-values of hESCs treated with plCSA-BNPs at $0.2,0.4,0.6,0.8,1$ and $2 \mu \mathrm{g} / \mathrm{ml}$ compared with that of cells treated with free BRU were $0.0243,0.0002$, $<0.0001,<0.0001,<0.0001$ and $<0.0001$, respectively. The P-values of BEAS-2B cells treated with plCSA-BNPs at 0.2 , $0.4,0.6,0.8,1$ and $2 \mu \mathrm{g} / \mathrm{ml}$ compared with that of cells treated with free BRU were $0.0422,0.0153,0.0005,<0.0001,<0.0001$ and $<0.0001$, respectively. According to the $\mathrm{IC}_{50}$ values of these NPs and free BRU, we analyzed the advantages of the targeting NPs. The $\mathrm{IC}_{50}$ of plCSA-BNPs $(9.767 \mu \mathrm{g} / \mathrm{ml})$ in IOSE80 cells was significantly higher compared with that of free BRU $(1.863 \mu \mathrm{g} / \mathrm{ml})$. The $\mathrm{IC}_{50}$ of plCSA-BNPs $(5.492 \mu \mathrm{g} / \mathrm{ml})$ in hESCs was significantly higher compared with that of free BRU $(1.8243 \mu \mathrm{g} / \mathrm{ml})$. The $\mathrm{IC}_{50}$ of plCSA-BNPs $(8.262 \mu \mathrm{g} / \mathrm{ml})$ in BEAS-2B cells was significantly higher compared with that of free BRU $(1.938 \mu \mathrm{g} / \mathrm{ml})$. These results demonstrated that BNPs combined with plCSA-BP effectively reduced the cytotoxicity compared with that of free $\mathrm{BRU}(\mathrm{P}<0.05$; Fig. 2A). Moreover, to further verify these findings, the 
A

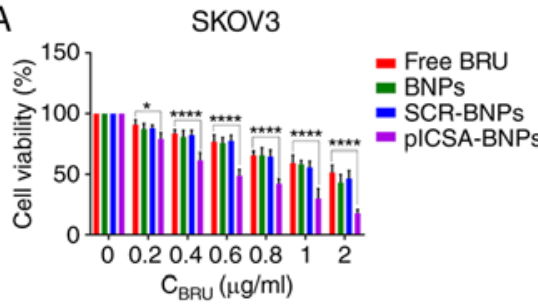

HEC-1-A

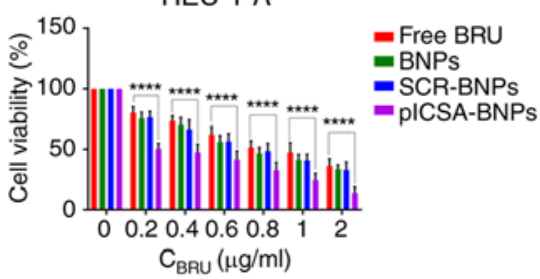

A549

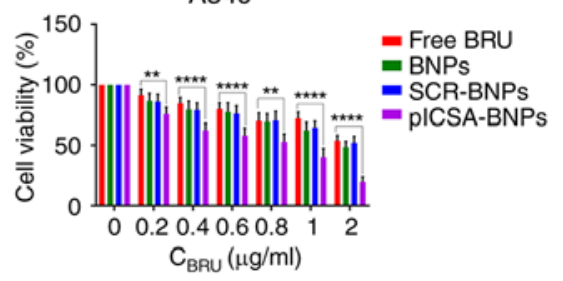

B
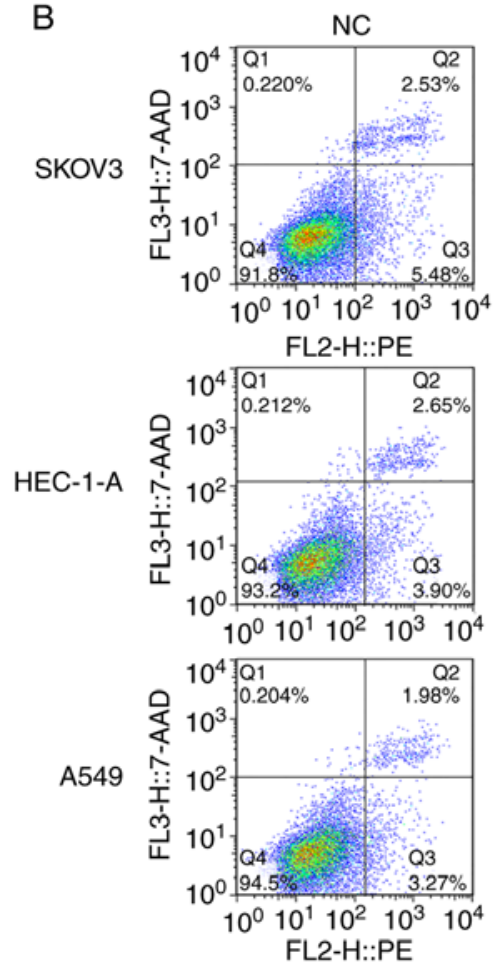
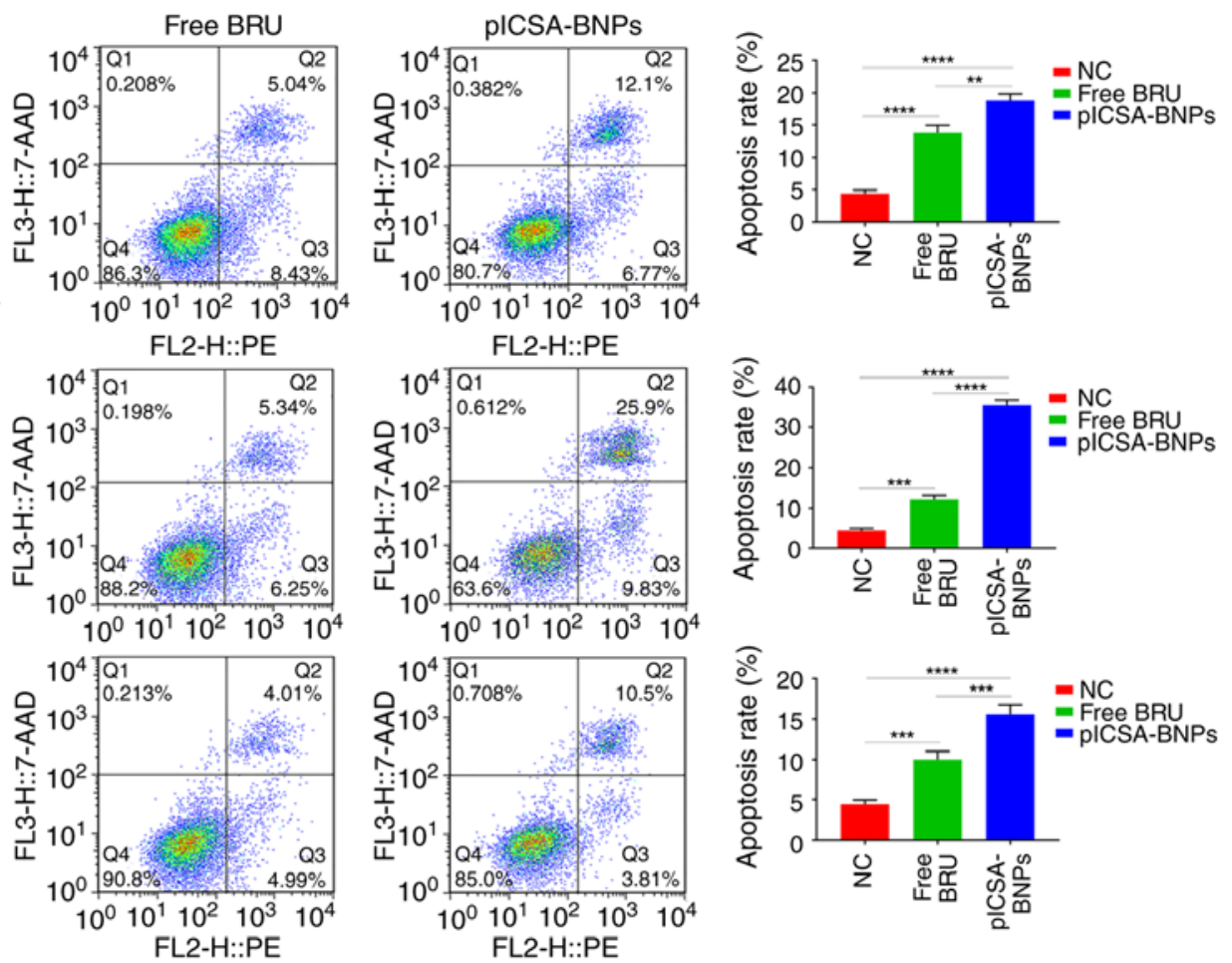

Figure 3. Growth inhibition of cell lines by plCSA-BNPs. (A) Quantitative evaluation of the viability of different cancer cells treated with free BRU and the different nanoparticles for $24 \mathrm{~h}$ using the Cell Counting Kit- 8 assay. Two-way ANOVA was used to analyze the significance of the differences among groups, followed by Bonferroni's post hoc test. (B) After stimulation with free BRU and the different nanoparticles for $24 \mathrm{~h}$, the apoptosis rate of different cancer cells was detected using flow cytometry. One-way ANOVA was used to analyze the significance of the differences among groups, followed by Tukey's post hoc test. Values are expressed as means \pm standard deviation. ${ }^{*} \mathrm{P}<0.05,{ }^{* *} \mathrm{P}<0.01,{ }^{* * *} \mathrm{P}<0.001,{ }^{* * * *} \mathrm{P}<0.0001$. The experiments were repeated three times. BRU, brusatol; SCR, scramble; plCSA, placental chondroitin sulfate A; BNPs, BRU-loaded nanoparticles; NC, negative control.

ratios of apoptotic cells were detected using flow cytometry. The apoptosis rates of IOSE80, hESCs and BEAS-2B cells treated with plCSA-BNPs were $7.000 \pm 0.289,6.033 \pm 0.145$ and $6.133 \pm 0.240 \%$, respectively, while those of IOSE80, hESCs and BEAS-2B cells treated with free BRU were 11.500 \pm 0.252 , $11.267 \pm 0.371$ and $11.067 \pm 0.521 \%$, respectively, which demonstrated that the apoptosis rates in cells treated with BRU were $1.6(\mathrm{P}<0.0001), 1.8(\mathrm{P}<0.0001)$ and $1.8(\mathrm{P}=0.0002)$ times higher compared with those in cells treated with free plCSA-BNPs (Fig. 2B). The results indicated that free BRU increased the apoptosis of normal cells, whereas plCSA-BP could reduce this effect. These in vitro results suggested that plCSA-BNPs could reduce cytotoxicity compared with that of free BRU.

plCSA-BNPs strongly inhibits tumor cell growth. To confirm the antitumor activity of BRU and plCSA-BNPs, the CCK-8 assay was used to evaluate cell viability after $24 \mathrm{~h}$ of treatment with different NPs. The results demonstrated that BRU significantly inhibited the activity of the three types of cancer cells, and both targeted (plCSA-BNPs) and non-targeted
(BNPs and SCR-BNPs) NPs exhibited dose-dependent cytotoxicity. When the dosage was $0.2-2 \mu \mathrm{g} / \mathrm{ml}$, the killing effect of plCSA-BNPs on SKOV3, HEC-1-A and A549 cells was stronger compared with that of BNPs and SCR-BNPs (Fig. 3A). The P-values of SKOV3 cells treated with plCSA-BNPs at $0.2,0.4,0.6,0.8,1$ and $2 \mu \mathrm{g} / \mathrm{ml}$ compared with that of cells treated with free BRU were 0.0173, <0.0001, $<0.0001,<0.0001,<0.0001$ and $<0.0001$, respectively. The P-values of HEC-1-A cells treated with plCSA-BNPs at 0.2, $0.4,0.6,0.8,1$ and $2 \mu \mathrm{g} / \mathrm{ml}$ compared with that of cells treated with free BRU were $<0.0001,<0.0001,<0.0001,0.0004$, $<0.0001$ and $<0.0001$, respectively. The P-values of A549 cells treated with plCSA-BNPs at 0.2, 0.4, 0.6, 0.8, 1 and $2 \mu \mathrm{g} / \mathrm{ml}$ compared with that of cells treated with free BRU were 0.0055 , $<0.0001,<0.0001,0.002,<0.0001$ and $<0.0001$, respectively. According to the $\mathrm{IC}_{50}$ values of these NPs and free BRU, the advantages of the targeting NPs were analyzed. The $\mathrm{IC}_{50}$ of plCSA-BNPs $(0.5734 \mu \mathrm{g} / \mathrm{ml})$ in SKOV3 cells was significantly lower compared with that of free BRU $(1.832 \mu \mathrm{g} / \mathrm{ml})$. The $\mathrm{IC}_{50}$ of plCSA-BNPs $(0.2378 \mu \mathrm{g} / \mathrm{ml})$ in HEC-1-A cells was significantly lower compared with that of free BRU 
A

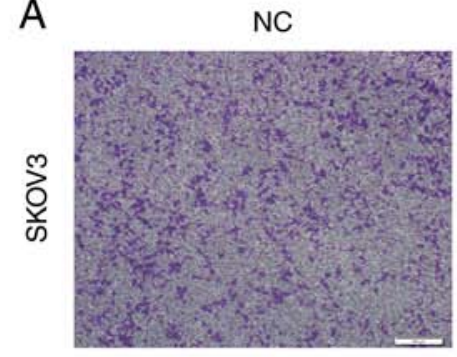

$\mathrm{B}$

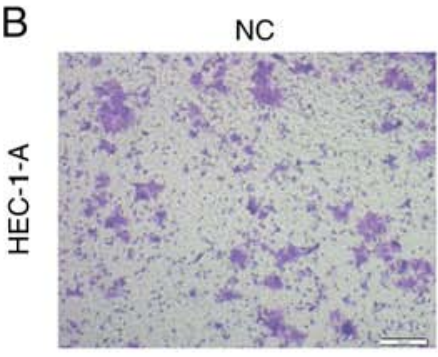

C

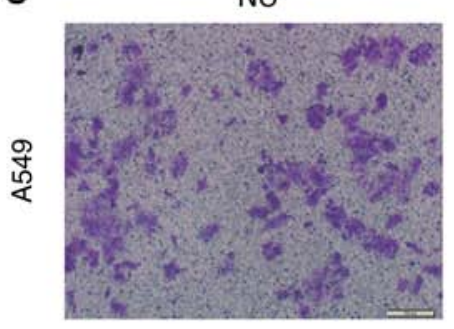

Free BRU

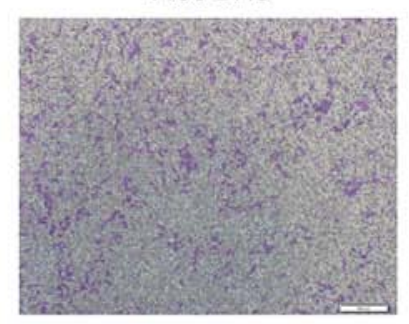

Free BRU

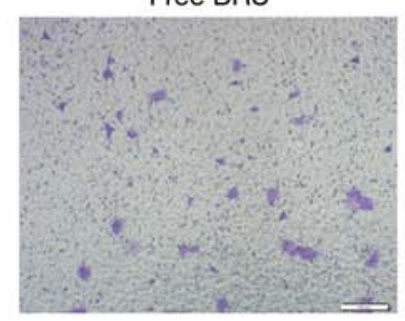

Free BRU

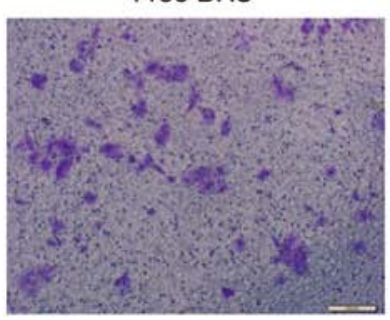

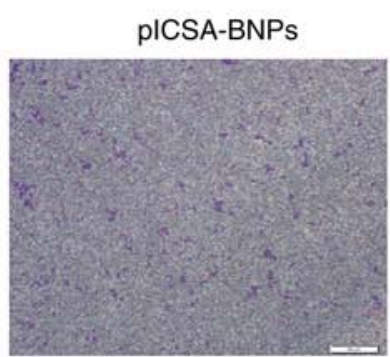
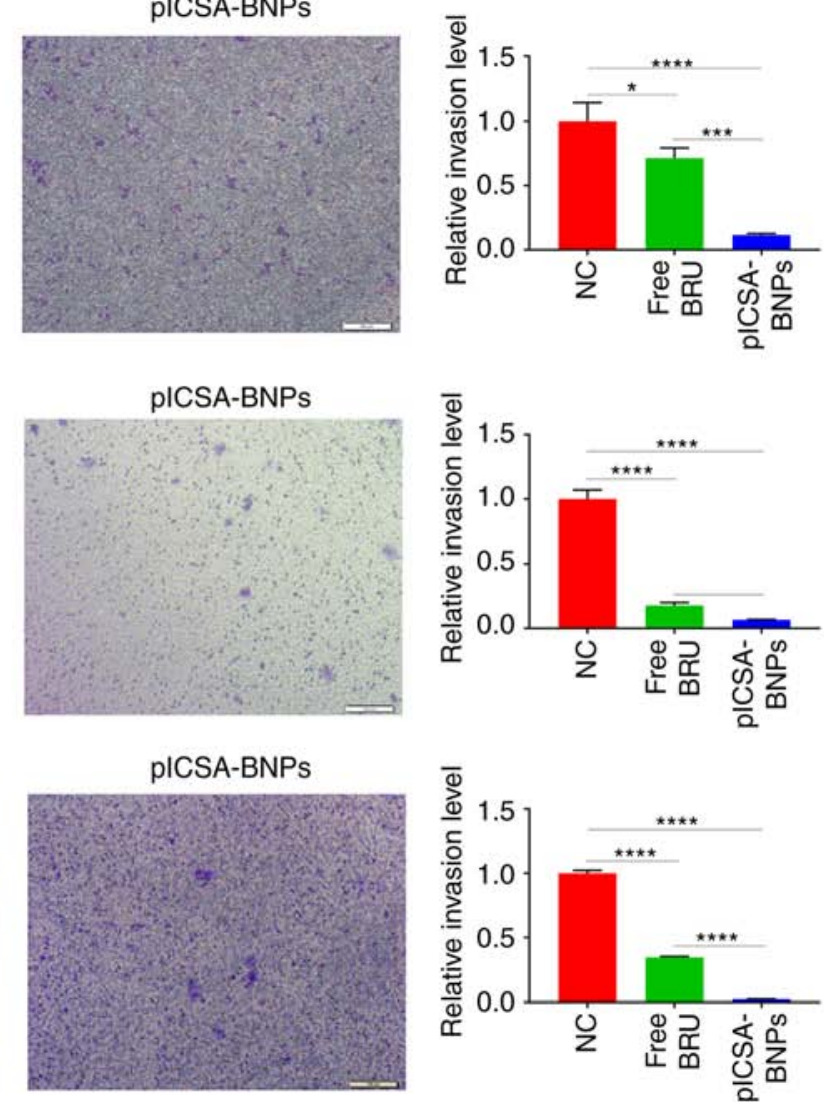

Figure 4. Invasion inhibition of cell lines by plCSA-BNPs. Examination of the invasiveness of (A) human ovarian adenocarcinoma SKOV3 cells, (B) human endometrial adenocarcinoma HEC-1-A cells and (C) human epithelial lung adenocarcinoma A549 cells treated with free BRU and the plCSA-BNPs for $24 \mathrm{~h}$ using the Transwell assay. One-way ANOVA was used to analyze the significance of the differences among groups, followed by Tukey's post hoc test. Values are expressed as means \pm standard deviation. ${ }^{*} \mathrm{P}<0.05,{ }^{* * *} \mathrm{P}<0.001,{ }^{* * * * *} \mathrm{P}<0.0001$. The experiments were repeated three times. Scale bar, $100 \mu \mathrm{m}$. BRU, brusatol; plCSA, placental chondroitin sulfate A; BNPs, BRU-loaded nanoparticles; NC, negative control.

$(0.975 \mu \mathrm{g} / \mathrm{ml})$. The $\mathrm{IC}_{50}$ of plCSA-BNPs $(0.7084 \mu \mathrm{g} / \mathrm{ml})$ in A549 cells was significantly lower compared with that of free BRU $(2.364 \mu \mathrm{g} / \mathrm{ml})$. These results suggested that conjugating the BNPs with plCSA-BP effectively improved the growth inhibition of tumor cells compared with that of free BRU $(\mathrm{P}<0.05$; Fig. 3A). Moreover, to further verify the findings mentioned above, the ratios of apoptotic cells were detected using flow cytometry. The apoptosis rates of SKOV3, HEC-1-A and A549 cells treated with plCSA-BNPs were $18.867 \pm 0.593$, $35.533 \pm 0.742$ and $15.60 \pm 0.702 \%$, respectively, while those of SKOV3, HEC-1-A and A549 cells treated with free BRU were $13.933 \pm 0.581,12.033 \pm 0.578$ and $10.00 \pm 0.577 \%$, respectively, which demonstrated that the apoptosis rates in cells treated with plCSA-BNPs were $1.3(\mathrm{P}=0.0012), 2.9(\mathrm{P}<0.0001)$ and $1.5(\mathrm{P}=0.0009)$ times higher compared with those treated with free BRU (Fig. 3B). These results demonstrated that free BRU increased cell apoptosis, whereas plCSA-BP further enhanced this effect. These in vitro results suggested that plCSA-BNPs may be a suitable candidate for cancer therapy.

plCSA-BNPs strongly inhibit tumor cell invasion. Transwell experiments were used to compare the effects of free BRU and plCSA-BNPs on cell invasion. In SKOV3, HEC-1-A and A549 cells, the cell invasion inhibition rates of the plCSA-BNPs group were $6.2(\mathrm{P}=0.0007), 2.6(\mathrm{P}=0.0429)$ and $9.6(\mathrm{P}<0.0001)$ times higher compared with those of the BRU group, respectively.
These results demonstrated that plCSA-BNPs significantly inhibited cell invasion (Fig. 4A-C).

plCSA-BNPs strongly inhibit tumor cell migration. Wound healing assays were performed to compare the effects of plCSA-BNPs and free BRU on cell migration. In SKOV3, HEC-1-A and A549 cells, the cell migration inhibition rates of the plCSA-BNPs group were $3(\mathrm{P}<0.0001), 3.6(\mathrm{P}<0.0001)$ and $5.9(\mathrm{P}<0.0001)$ times higher compared with those of the BRU group, respectively. These results demonstrated that plCSA-BNPs significantly inhibited cell migration compared with the control group (Fig. 5A-C).

plCSA-BNPs inhibit cancer cell proliferation, invasion and migration by regulating the BCL2/BAX, cleaved caspase- 3 and MMP pathways. To explore the molecular mechanisms underlying the effects of BRU on cancer cells, the SKOV3 cell line was selected, treated with BRU and the different NPs, and then western blotting was used to study the levels of apoptosis-related proteins, such as BCL2, BAX and cleaved caspase-3, and migration- and invasion-related proteins, such as MMP-2 and MMP-9. The levels of the apoptosis-related proteins BCL2, BAX and cleaved caspase-3, as well as those of the migration- and invasion-related proteins MMP-2 and MMP-9 are shown in Fig. 6B. Treatment with free BRU resulted in significant downregulation of BCL2, MMP-2 

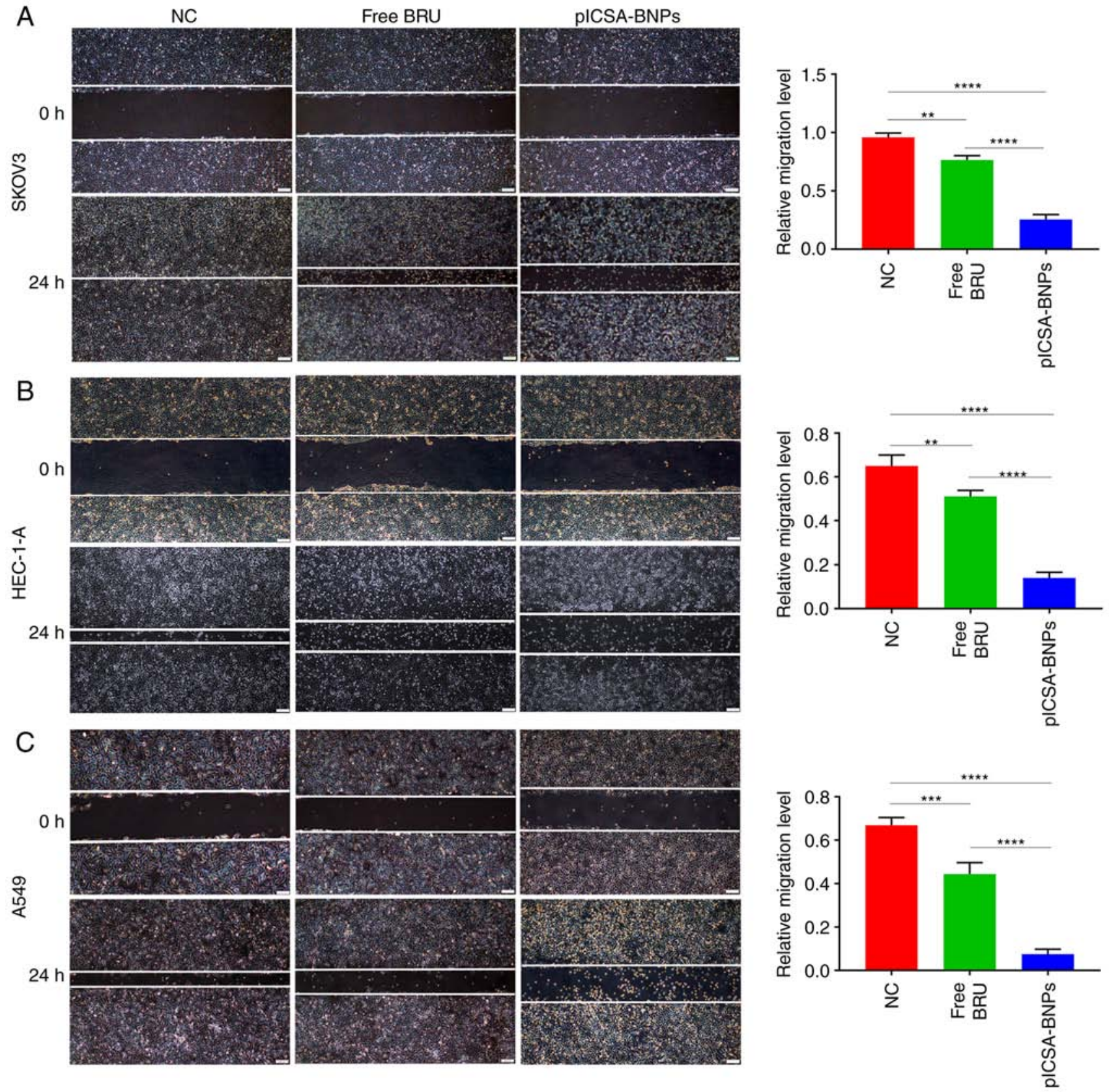

Figure 5. Migration capacity inhibition of cell lines by plCSA-BNPs. Examination of the migration capacity of (A) human ovarian adenocarcinoma SKOV3 cells, (B) human endometrial adenocarcinoma HEC-1-A cells and (C) human epithelial lung adenocarcinoma A549 cells treated with free BRU and the plCSA-BNPs for $24 \mathrm{~h}$ using a scratch test. One-way ANOVA was used to analyze the significance of the differences among groups, followed by Tukey's post hoc test. Values are expressed as means \pm standard deviation. ${ }^{* *} \mathrm{P}<0.01,{ }^{* * *} \mathrm{P}<0.001,{ }^{* * * * *} \mathrm{P}<0.0001$. The experiments were repeated three times. Scale bar, $200 \mu \mathrm{m}$. BRU, brusatol; plCSA, placental chondroitin sulfate A; BNPs, BRU-loaded nanoparticles; NC, negative control.

and MMP-9 levels, and upregulation of BAX and cleaved caspase-3 levels, compared with those in the control group. In addition, the same expression trends were observed following plCSA-BNPs treatment for $24 \mathrm{~h}$; however, the protein levels were altered to a greater degree compared with those after free BRU treatment. For BCL2, BAX, cleaved caspase-3, MMP-2 and MMP-9, the changes the protein levels in the plCSA-BNPs group were 2 ( $\mathrm{P}=0.0028), 2.2(\mathrm{P}=0.0192), 2(\mathrm{P}=0.0185), 3.5$ $(\mathrm{P}<0.0001)$, and $2(\mathrm{P}<0.0001)$ times greater compared with those in the BRU group, respectively. These results indicated that BRU promoted cancer cell death by inhibiting cancer cell proliferation, invasion and migration, whereas encapsulating BRU as plCSA-BNPs enhanced these effects.

\section{Discussion}

BRU has notable anticancer activity and may improve disease outcomes in various cancers $(34,35)$. However, BRU is associated with a number of toxic adverse effects (10-16), which may limit its application in the clinical setting. Nanocarriers are promising systems for the effective treatment of cancer $(36,37)$. As mentioned above, glycosaminoglycan plCSA is specifically expressed in most cancer cells and placental trophoblasts. Therefore, plCSA-NPs may be used in targeted therapy of human tumor cells. Thus, it was hypothesized that encapsulating BRU in plCSA-modified NPs would prevent its inherent side effects (36). In the present study, plCSA-BP-conjugated 

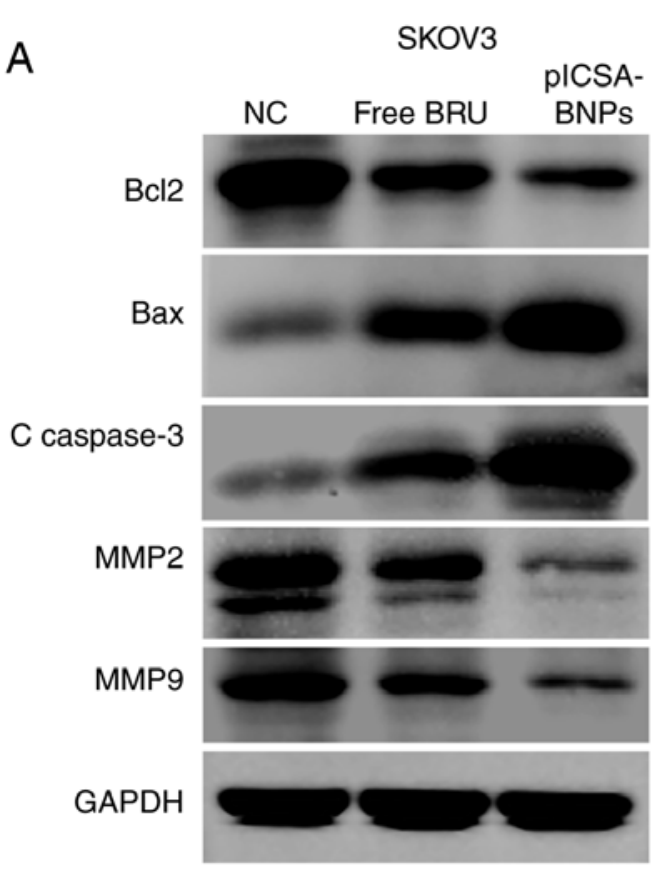
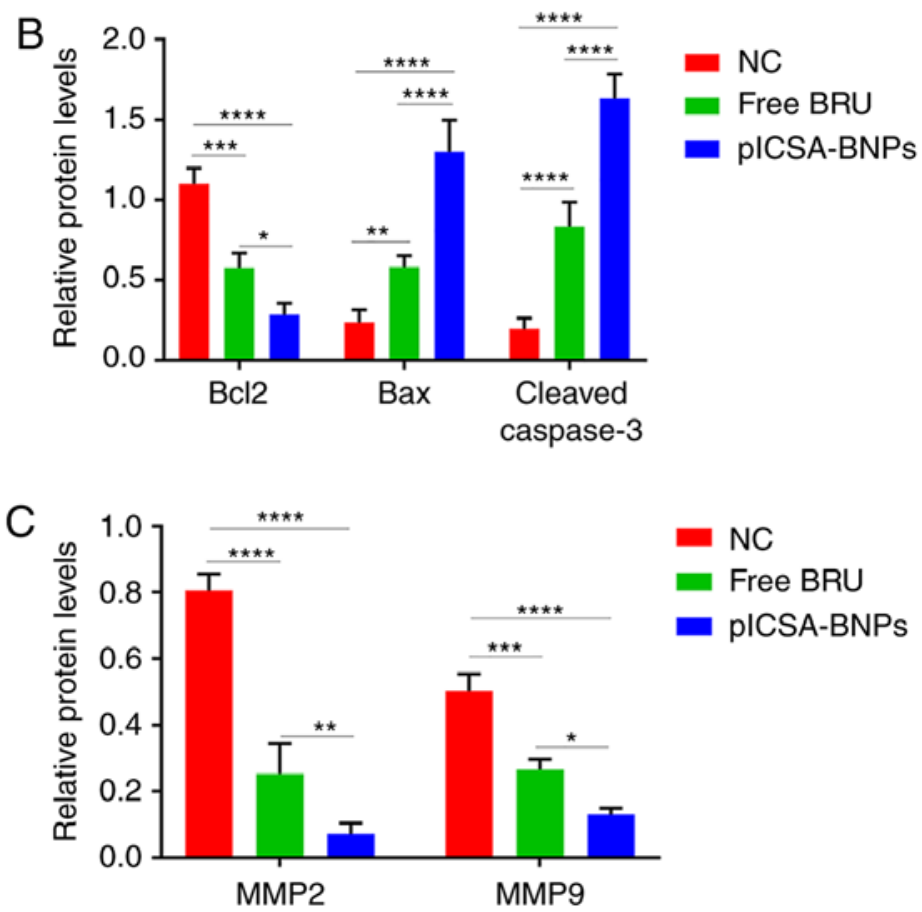

Figure 6. plCSA-BNPs promote cancer cell death by regulating the BCL2/BAX, cleaved caspase-3 and MMP pathways. Western blotting demonstrated that cancer cells treated with the plCSA-BNPs exhibited significant downregulation of BCL2, MMP2 and MMP 9 levels and upregulation of BAX and cleaved caspase-3 levels. (A) Representative immunoblots of BCL2, BAX, cleaved caspase-3, MMP-2 and MMP-9. GAPDH was used as the internal control. (B) Densitometry results of BCL2, BAX and cleaved caspase-3 as analyzed using ImageJ software. (C) Densitometry of MMP-2 and MMP-9 results as analyzed using ImageJ software. One-way ANOVA was used to analyze the significance of the differences among groups, followed by Tukey's post hoc test. Values are expressed as means \pm standard deviation. ${ }^{*} \mathrm{P}<0.05,{ }^{* *} \mathrm{P}<0.01,{ }^{* * *} \mathrm{P}<0.001,{ }^{* * * * *} \mathrm{P}<0.0001$. The experiments were repeated three times. BRU, brusatol; plCSA, placental chondroitin sulfate A; BNPs, BRU-loaded nanoparticles; NC, negative control; BCL2, B-cell lymphoma 2; BAX, BCL2-associated X protein; MMP, matrix metallopeptidase.

lipid-polymer NPs loaded with BRU (plCSA-BNPs) were synthesized. We observed that the uptake of plCSA-BP modified NPs by cancer cells was markedly higher compared with that of other types of NPs. Three different cancer cell lines were treated with free BRU, BNPs, SCR-BNPs or plCSA-BNPs. The results demonstrated that plCSA-BNPs promoted the apoptosis of cancer cells more effectively, and inhibited the proliferation, invasion and migration of cancer cells by regulating the BCL2, BAX, cleaved caspase-3, MMP-2 and MMP-9 pathways. The results of the present study will hopefully improve our understanding of the successful application of plCSA-BP modified NPs and provide an effective tool for targeted drug delivery to cancer cells. These plCSA targeting lipid polymer NPs may be used to deliver drugs that target most human cancers, thereby representing a breakthrough in the targeted therapy of cancer and supporting the development of new drug targeting methods for traditional Chinese medicines.

The EE and LE of drugs in NPs are crucial for their success as drug delivery systems (33). It was reported that the particles were more stable when the drug loading levels were lower (38). Furthermore, the drug loading amount is a key factor for the drug EE (38). Therefore, in the present study, loading of small drug amounts was performed to ensure that the prepared NPs were more stable.

Previous studies demonstrated that tumor cells display good uptake of liposome polymer NPs $(38,39)$. For example, Chu et al proved that PEGPE/PLGA NPs exhibited higher drug loading, less sudden release, good serum stability and higher cell uptake compared with traditional PLGA NPs (40).
The results of the present study demonstrated that tumor cells were also capable of taking up plCSA-CNPs, which is consistent with previous research results (39-41). Our data suggested that plCSA-BNPs efficiently delivered drugs into tumor cells to eliminate them.

BRU has been shown to modulate the apoptosis, migration and invasion of human cancer cells (42), indicating its potential role in cancer metastasis. Therefore, CCK-8 and cell apoptosis assays were used to study the effects of BRU and different NPs on tumor cells and normal cells. The effects of BRU and different NPs on tumor cells were studied using migration and Transwell invasion assays. The cytotoxicity of targeted (plCSA-BNPs) and non-targeted (BNPs and SCR-BNPs) NPs against normal cells was less prominent compared with that of free BRU, while BRU exerted a significant inhibitory effect on the tumor cells, and both targeted (plCSA-BNPs) and non-targeted (BNPs and SCR-BNPs) NPs exhibited dose-dependent cytotoxicity. When the drug concentration was $0.2-2 \mu \mathrm{g} / \mathrm{ml}$, the killing effect of plCSA-BNPs on SKOV3, HEC-1-A and A549 cells was stronger compared with that of free BRU, BNPs and SCR-BNPs, suggesting that the combination of BNPs and plCSA-BP significantly enhanced the growth inhibitory and pro-apoptotic effect of BRU on tumor cells. Moreover, plCSA-BNPs could significantly reduce the killing effect of BRU on normal cells. Thus, the NPs maintained the antitumor activity of BRU and reduced its toxicity toward non-tumor cells. The process of tumorigenesis and development is extremely complex. In the present study, one cell line was selected, treated with BRU 
and the different NPs, and western blotting was further employed to examine the levels of apoptosis-related proteins and migration- and invasion-related proteins. Apoptosis may occur through two pathways: Extrinsic and intrinsic. However, there is now evidence that these two pathways are interrelated, with molecules in one pathway affecting the other (43). There is an additional pathway that involves T-cell mediated cytotoxicity and perforin-granzyme-dependent killing of cells. This perforin/granzyme pathway can induce apoptosis via either granzyme B or granzyme A. The extrinsic, intrinsic and granzyme B pathways converge on the same terminal, or execution, pathway. This pathway is initiated by the cleavage of caspase-3 (44), and the direct activation of caspase- 3 is essential for granzyme B-induced cell killing (45). It has been reported that members of the BCL2 family regulate the process of apoptosis, including anti-apoptotic and pro-apoptotic transcription factors, such as BCL2 and BAX, respectively. The activity of BAX leads to cytochrome $c$ release to promote apoptosis. By contrast, as an anti-apoptotic protein, BCL2 can prevent apoptosis-related death (46). BRU may also inhibit invasion, migration and epithelial-to-mesenchymal transition (42). The interaction between apoptotic and anti-apoptotic proteins determines cell survival. Members of the MMP family are associated with cell migration and invasion. MMP-2 and MMP-9 are the two most extensively investigated members of the MMP family (47). In accordance with previous studies, we found that among the three groups, the levels of cleaved caspase-3 were significantly higher in the plCSA-BNPs group. Therefore, plCSA-BNPs significantly increased the transformation of the inactive procaspase- 3 to active cleaved caspase-3, which is the main inducer of apoptosis. plCSA-BNPs promoted the levels of pro-apoptotic factors by significantly increasing the expression of pro-apoptotic BAX. A slight reduction in the levels of the anti-apoptotic BCL2 protein was also observed. In addition, the plCSA-BNPs strongly inhibited the expression of migration- and invasion-related proteins, such as MMP-2 and MMP-9. These results demonstrated that BRU, delivered via plCSA-modified NPs, may play a key role in promoting cancer cell apoptosis and inhibiting invasion and migration via regulation of important related proteins.

In conclusion, as a drug delivery system, plCSA-BP-conjugated lipid polymer NPs loaded with BRU exerted a notable antitumor effect in vitro, which could provide the basis for the development of new anticancer drug delivery systems.

\section{Acknowledgements}

Not applicable.

\section{Funding}

This study was supported by the National Key Research and Development Program of China (grant nos. 2018YFC1004103, 2018YFC1002804 and 2016YFC1000600), the National Natural Science Foundation of China (grant nos. 81571513, 81771662 and 81771618), the National Key Natural Projects (grant no. 81830041), the National Natural Sciences Foundation (grant nos. 81771617 and 81771611), and the Shenzhen Basic Research Fund (grant no. JCYJ20170412140326739).

\section{Availability of data and materials}

All data generated or analyzed during the present study are included in this published article.

\section{Authors' contributions}

JY and XF were involved in the study design and revision of the manuscript. $\mathrm{XC}, \mathrm{TY}$ and $\mathrm{BZ}$ performed all the experiments and drafted the manuscript. XC, TY, BZ, JC, TX, BW, ML and BS performed data acquisition. XC, TY and BZ performed data analysis. All the authors have read and approved the final manuscript.

\section{Ethics approval and consent to participate}

Not applicable.

\section{Patient consent for publication}

Not applicable.

\section{Competing interests}

All the authors declare that they have no competing interests.

\section{References}

1. Kitagawa I, Mahmud T, Simanjuntak P, Hori K, Uji T and Shibuya H: Indonesian medicinal plants. VIII. Chemical structures of three new triterpenoids, bruceajavanin A, dihydrobruceajavanin $\mathrm{A}$, and bruceajavanin $\mathrm{B}$, and a new alkaloidal glycoside, bruceacanthinoside, from the stems of Brucea javanica (Simaroubaceae). Chem Pharm Bull (Tokyo) 42: 1416-1421, 1994.

2. Liu JH, Qin JJ, Jin HZ, Hu XJ, Chen M, Shen YH, Yan SK and Zhang WD: A new triterpenoid from Brucea javanica. Arch Pharm Res 32: 661-666, 2009.

3. Cuendet M and Pezzuto JM: Antitumor activity of bruceantin: An old drug with new promise. J Nat Prod 67: 269-272, 2004.

4. Tang W, Xie J, Xu S, Lv H, Lin M, Yuan S, Bai J, Hou Q and Yu S: Novel nitric oxide-releasing derivatives of brusatol as anti-inflammatory agents: Design, synthesis, biological evaluation, and nitric oxide release studies. J Med Chem 57: 7600-7612, 2014.

5. Oh ET, Kim CW, Kim HG, Lee JS and Park HJ: Brusatol-mediated inhibition of c-myc increases HIF-1 $\alpha$ degradation and causes cell death in colorectal cancer under hypoxia. Theranostics 7: 3415-3431, 2017.

6. Lu Z, Lai ZQ, Leung AWN, Leung PS, Li ZS and Lin ZX: Exploring brusatol as a new anti-pancreatic cancer adjuvant: Biological evaluation and mechanistic studies. Oncotarget 8: 84974-84985, 2017.

7. Ren D, Villeneuve NF, Jiang T, Wu T, Lau A, Toppin HA and Zhang DD: Brusatol enhances the efficacy of chemotherapy by inhibiting the Nrf2-mediated defense mechanism. Proc Natl Acad Sci USA 108: 1433-1438, 2011.

8. Olayanju A, Copple IM, Bryan HK, Edge GT, Sison RL, Wong MW, Lai ZQ, Lin ZX, Dunn K, Sanderson CM, et al: Brusatol provokes a rapid and transient inhibition of Nrf2 signaling and sensitizes mammalian cells to chemical toxicity-implications for therapeutic targeting of Nrf2. Free Radic Biol Med 78: 202-212, 2015.

9. Zhang L, Feng X, Ma D, Yang J, Jiang H, Zhang Y and He W: Brusatol isolated from Brucea javanica (L.) Merr. induces apoptotic death of insect cell lines. Pestic Biochem Physiol 107: 18-24, 2013.

10. Xiao C, Xia ML, Wang J, Zhou XR, Lou YY, Tang LH, Zhang FJ, Yang JT and Qian LB: Luteolin attenuates cardiac ischemia/reperfusion injury in diabetic rats by modulating nrf2 antioxidative function. Oxid Med Cell Longev 2019: 2719252, 2019. 
11. Zhang X, Lai W, Ying X, Xu L, Chu K, Brown J, Chen L and Hong G: Salidroside reduces inflammation and brain injury after permanent middle cerebral artery occlusion in rats by regulating $\mathrm{PI} 3 \mathrm{~K} / \mathrm{PKB} / \mathrm{Nrf} 2 / \mathrm{NFKB}$ signaling rather than complement $\mathrm{C} 3$ activity. Inflammation 42: 1830-1842, 2019.

12. Huang Y, Zhou F, Shen C, Wang H and Xiao Y: LBP reduces theinflammatory injuryof kidney in septic rat and regulates the Keap1-Nrf2ARE signaling pathway1. Acta Cir Bras 34: e20190010000003, 2019.

13. Lu Y, Wu S, Xiang B, Li L and Lin Y: Curcumin attenuates oxaliplatin-induced liver injury and oxidative stress by activating the Nrf2 pathway. Drug Des Devel Ther 14: 73-85, 2020.

14. Han X, Yao W, Liu Z, Li H, Zhang ZJ, Hei Z and Xia Z: Lipoxin A4 preconditioning attenuates intestinal ischemia reperfusion injury through Keap1/Nrf2 pathway in a lipoxin A4 receptor independent manner. Oxid Med Cell Longev 2016: 9303606, 2016.

15. Lin Y, Sui LC, Wu RH, Ma RJ, Fu HY, Xu JJ, Qiu XH and Chen L: Nrf2 inhibition affects cell cycle progression during early mouse embryo development. J Reprod Dev 64: 49-55, 2018

16. Ma R, Li H, Zhang Y, Lin Y, Qiu X, Xie M and Yao B: The toxic effects and possible mechanisms of Brusatol on mouse oocytes. PLoS One 12: e0177844, 2017.

17. Kumar A, Sharma PR and Mondhe DM: Potential anticancer role of colchicine-based derivatives: An overview. Anticancer Drugs 28: 250-262, 2017.

18. Siegel RL, Miller KD and Jemal A: Cancer statistics, 2018. CA Cancer J Clin 68: 7-30, 2018.

19. Bray F, Ferlay J, Soerjomataram I, Siegel RL, Torre LA and Jemal A: Global cancer statistics 2018: GLOBOCAN estimates of incidence and mortality worldwide for 36 cancers in 185 countries. CA Cancer J Clin 68: 394-424, 2018.

20. Guo L, Liu Z and Tang X: Overexpression of SLFN5 induced the epithelial-mesenchymal transition in human lung cancer cell line A549 through $\beta$-catenin/Snail/E-cadherin pathway. Eur J Pharmacol 862: 172630, 2019.

21. Gao S, Bian T, Zhang Y, Su M and Liu Y: TCF12 overexpression as a poor prognostic factor in ovarian cancer. Pathol Res Pract 215: 152527, 2019

22. Zhou X, Shi H, Jiang G, Zhou Y and Xu J: Antitumor activities of ginseng polysaccharide in C57BL/6 mice with Lewis lung carcinoma. Tumour Biol 35: 12561-12566, 2014.

23. Zhou ML, Chen FS and Mao H: Clinical significance and role of up-regulation of SERPINA3 expression in endometrial cancer. World J Clin Cases 7: 1996-2002, 2019.

24. Yang T, Zhou R, Yu S, Yu S, Cui Z, Hu P, Liu J, Qiao Q and Zhang J: Cytoplasmic SIRT1 inhibits cell migration and invasion by impeding epithelial-mesenchymal transition in ovarian carcinoma. Mol Cell Biochem 459: 157-169, 2019.

25. Zeng L, Gupta P, Chen Y, Wang E, Ji L, Chao H and Chen ZS The development of anticancer ruthenium(ii) complexes: From single molecule compounds to nanomaterials. Chem Soc Rev 46: 5771-5804, 2017

26. Geiger S, Lange V, Suhl P, Heinemann V and Stemmler HJ: Anticancer therapy induced cardiotoxicity: Review of the literature. Anticancer Drugs 21: 578-590, 2010.

27. McDaid WJ, Greene MK, Johnston MC, Pollheimer E, Smyth P, McLaughlin K, Van Schaeybroeck S, Straubinger RM, Longley DB and Scott CJ: Repurposing of cetuximab in antibody-directed chemotherapy-loaded nanoparticles in EGFR therapy-resistant pancreatic tumours. Nanoscale 11: 20261-20273, 2019.

28. Zheng W, Wang C,Ding R,Huang Y,Li Y and Lu Y:Triptolide-loaded nanoparticles targeting breast cancer in vivo with reduced toxicity. Int J Pharm 572: 118721, 2019

29. Benguigui M, Weitz IS, Timaner M, Kan T, Shechter D, Perlman O, Sivan S, Raviv Z, Azhari H and Shaked Y: Copper oxide nanoparticles inhibit pancreatic tumor growth primarily by targeting tumor initiating cells. Sci Rep 9: 12613, 2019.

30. Alavi SE, Muflih Al Harthi S, Ebrahimi Shahmabadi H and Akbarzadeh A: Cisplatin-loaded polybutylcyanoacrylate nanoparticles with improved properties as an anticancer agent. Int J Mol Sci 20: 1531, 2019.
31. Yang B, Liu H, Yang H, Chen W, Wu J, Feng X, Tong R, Yu H, Chen Y, Lv Z, et al: Combinatorial photochemotherapy on liver cancer stem cells with organoplatinum(ii) metallacage-based nanoparticles. J Mater Chem B 7: 6476-6487, 2019.

32. Salanti A,Clausen TM, Agerbaek MO, Al Nakouzi N, Dahlback M, Oo HZ, Lee S, Gustavsson T, Rich JR, Hedberg BJ, et al: Targeting human cancer by a glycosaminoglycan binding malaria protein. Cancer Cell 28: 500-514, 2015.

33. Zhang B, Cheng G, Zheng M, Han J, Wang B, Li M, Chen J, Xiao T, Zhang J, Cai L, et al: Targeted delivery of doxorubicin by CSA-binding nanoparticles for choriocarcinoma treatment. Drug Deliv 25: 461-471, 2018

34. Lee JH, Rangappa S, Mohan CD, Basappa, Sethi G, Lin ZX, Rangappa KS and Ahn KS: Brusatol, a Nrf2 inhibitor targets STAT3 signaling cascade in head and neck squamous cell carcinoma. Biomolecules 9: 550, 2019.

35. Zhang J, Fang X, Li Z, Chan HF, Lin Z, Wang Y and Chen M: Redox-sensitive micelles composed of disulfide-linked Pluronic-linoleic acid for enhanced anticancer efficiency of brusatol. Int J Nanomedicine 13: 939-956, 2018.

36. Beg S, Kawish SM, Panda SK, Tarique M, Malik A, Afaq S, Al-Samghan AS, Iqbal J, Alam K and Rahman M: Nanomedicinal strategies as efficient therapeutic interventions for delivery of cancer vaccines. Semin Cancer Biol Oct 13, 2019 (Epub ahead of print).

37. Farokhzad OC, Cheng J, Teply BA, Sherifi I, Jon S, Kantoff PW, Richie JP and Langer R: Targeted nanoparticle-aptamer bioconjugates for cancer chemotherapy in vivo. Proc Natl Acad Sci USA 103: 6315-6320, 2006.

38. Lin WJ, Juang LW and Lin CC: Stability and release performance of a series of pegylated copolymeric micelles. Pharm Res 20: 668-673, 2003.

39. Wang G, Chen Y, Wang P, Wang Y, Hong H, Li Y, Qian J, Yuan Y, Yu B and Liu C: Preferential tumor accumulation and desirable interstitial penetration of poly(lactic-co-glycolic acid) nanoparticles with dual coating of chitosan oligosaccharide and polyethylene glycol-poly(D,L-lactic acid). Acta Biomater 29: 248-260, 2016.

40. Chu CH, Wang YC, Huang HY, Wu LC and Yang CS: Ultrafine PEG-coated poly(lactic-co-glycolic acid) nanoparticles formulated by hydrophobic surfactant-assisted one-pot synthesis for biomedical applications. Nanotechnology 22: 185601, 2011.

41. Zhang B, Zheng M, Cai L and Fan X: Synthesis and characterization of placental chondroitin sulfate A (plCSA)-targeting lipid-polymer nanoparticles. J Vis Exp 18: 58209, 2018.

42. Ye R, Dai N, He Q, Guo P, Xiang Y, Zhang Q, Hong Z and Zhang Q: Comprehensive anti-tumor effect of Brusatol through inhibition of cell viability and promotion of apoptosis caused by autophagy via the PI3K/Akt/mTOR pathway in hepatocellular carcinoma. Biomed Pharmacother 105: 962-973, 2018.

43. Igney FH and Krammer PH: Death and anti-death: Tumour resistance to apoptosis. Nat Rev Cancer 2: 277-288, 2002.

44. Elmore S: Apoptosis: A review of programmed cell death. Toxicol Pathol 35: 495-516, 2007.

45. Goping IS, Barry M, Liston P, Sawchuk T, Constantinescu G, Michalak KM, Shostak I, Roberts DL, Hunter AM, Korneluk R and Bleackley RC: Granzyme B-induced apoptosis requires both direct caspase activation and relief of caspase inhibition. Immunity 18: 355-365, 2003.

46. Korsmeyer SJ: BCL-2 gene family and the regulation of programmed cell death. Cancer Res 59 (7 Suppl): 1693S-1700S, 1999.

47. Jia YL, Shi L, Zhou JN, Fu CJ, Chen L, Yuan HF, Wang YF, Yan XL, Xu YC,Zeng Q, et al: Epimorphin promotes human hepatocellular carcinoma invasion and metastasis through activation of focal adhesion kinase/extracellular signal-regulated kinase/matrix metalloproteinase-9 axis. Hepatology 54: 1808-1818, 2011.

This work is licensed under a Creative Commons Attribution-NonCommercial-NoDerivatives 4.0 International (CC BY-NC-ND 4.0) License. 